\title{
Drill rig with a down-the-hole hammer for regulating the drilling rate by changing the air flow
}

\author{
$D$ Yungmeister, $E$ Gasimov \\ Saint-Petersburg Mining University, Department of Mechanical Engineering, 2 21 st Line V.O., 199106, Saint- \\ Petersburg, Russia
}

\begin{abstract}
At present, a lack of efficiency of the rotary drilling intensification can be observed at mining enterprises that employ drill rigs. Due to this, we propose to enhance the rotary drilling using shock loads by installing a down-the-hole (DTH) hammer into the drill string of the rig for roller drilling, for instance, SBSh-250. The paper discusses the issue related to an increase in the drilling rate using a drill rig with DTH hammer and adjustable valve that regulates the air flow. The paper considers different types of drilling in engineering and geological surveys. Rocks were sampled for various types of drilling. The physical and mechanical properties of rocks, which affect the drilling process, were considered. The study focuses on a significant increase in the drilling rate through an increase in the impact power. As part of the study, an improved drill rig with a down-the-hole hammer controlled by a radio receiver was developed. When analyzing the physical and mechanical properties, it was shown that the control of DTH hammer operation enables fast drilling of complex rocks without reducing the drilling rate. An increase in the drilling rate of self-propelled equipment using DTH hammers installed above the drill bit will reduce the cost of drilling and extend the service life of the working tool.
\end{abstract}

\section{Introduction}

At present, drilling-and-blasting (DB) is often used for hard rock development by the open method in both overburden and mining operations. The most timeconsuming operation in DB is drilling blast holes. In Russia, one of the most common drill rigs is SBSh250MNA-32. Therefore, the problem of increasing the drilling rate of such drill rigs is urgent. The drilling rate is observed to decrease during drilling of complex rocks with alternating hard and soft layers, for example, rocks in the open pit of JSC Apatit. [8]

The main developments that focus on improvement of SBSh 250 are aimed at increasing the drilling rate by the automated control of operating parameters or by various technical means used for drilling intensification [3].

To increase the drilling rate and improve the working conditions for SBSh during drilling complex rocks with alternating hard and soft layers, it is proposed to use DTH hammers [2,5,9], for instance, a hammer presented in Fig. 2. Its parameters can vary depending on the size of the inlet cross-section and on the increase in percussion action due to the air flow regulation using the adjustable valve.

The above problem can be solved when using the modernized drill rig with a standard pneumatic hammer
M48 with the shock impulse (impact force) divided into sub-impulses using a valve, which consists of two plates with holes installed one above the other and connected by a single rim.

\section{Materials and methods}

Various operation modes of DTH are achieved through changing the working pressure behind the valve when changing the size of the hole cross-section and, accordingly, local resistance to the air flow [7].

A significant decrease in the durability of the bit at high values of percussion action of the DTH hammer limits its use in conjunction with roller bits. We have shown that a significant reduction in stability can be eliminated if percussion action of the hammer does not exceed $20 \%$ of the axial force of the drill.

When using DTH with an adjustable valve in conjunction with pneumatic-hydraulic shock absorbers between the drill string and the rotation head, an insignificant change in the vibration level of the following massifs can be observed in drilling: relatively soft monolithic rocks, hard monolithic rocks or rocks with a complex structure.

The use of SBSh and DTH drill rigs with an adjustable valve can increase the average drilling rate for complex rock massifs, decrease the time for drilling

\footnotetext{
Corresponding author: emil.7.07.7.eq@gmail.com
} 
blocks in open pits, which, in turn, reduce the cost of DB and ore.

\section{Results and discussion}

\subsection{Physical and mechanical properties of rocks}

One of the main factors of rocks that affect drilling are physical and mechanical properties:

- mechanical strength,

- elasticity, plasticity,

- fragility,

- hardness,

- abrasiveness,

- density,

- buoyancy

- stability

The ability of rocks to resist fracture during compression, shearing, breaking and bending is called mechanical strength. For various rocks, the compressive strength is modified from $0.1-0.2$ to $500 \mathrm{MPa}(1 \mathrm{MPa} \approx$ $10 \mathrm{kgf} / \mathrm{cm}^{2}$ ). The strength of rocks mainly depends on the mineralogical composition, structure and porosity, the nature of the bond between grains, hardness and particle size, etc. For instance, fine-grained rocks exhibit greater strength than coarse-grained rocks.

The ability of a deformable body to restore its original shape and volume after load elimination is called elasticity. Resilience is also characterized by the rebound of the tool (bit) from the rock.

The ability of rocks to deform under the impact of applied forces, without breaking the continuity, and simultaneous bringing rocks to permanent deformation is called plasticity. Most of the minerals and hard rocks practically do not exhibit residual deformation, since their destruction occurs earlier than plastic properties begin to appear.

The ability of rocks to break into smaller pieces when exposed to percussion action without apparent plastic deformation is called brittleness. The manifestation of brittle properties depends on load duration. For instance, a slow loading rate can cause residual plastic deformations, and, conversely, a high loading rate can lead to the fact that viscous bodies manifest themselves as brittle.

The ability of rocks to resist the penetration of another solid body that does not receive residual deformations is called hardness. Hardness can be considered a special case of indentation strength. One of the most important properties of rocks, which determines the degree of penetration of the drill cutters and significantly affects the mechanical rate of drilling a well, is fragility. The destruction rate of rocks in drilling mainly depends on the aggregate hardness. The relative hardness of minerals according to Mohs scale is presented in Fig. 1.

\section{Hardness}

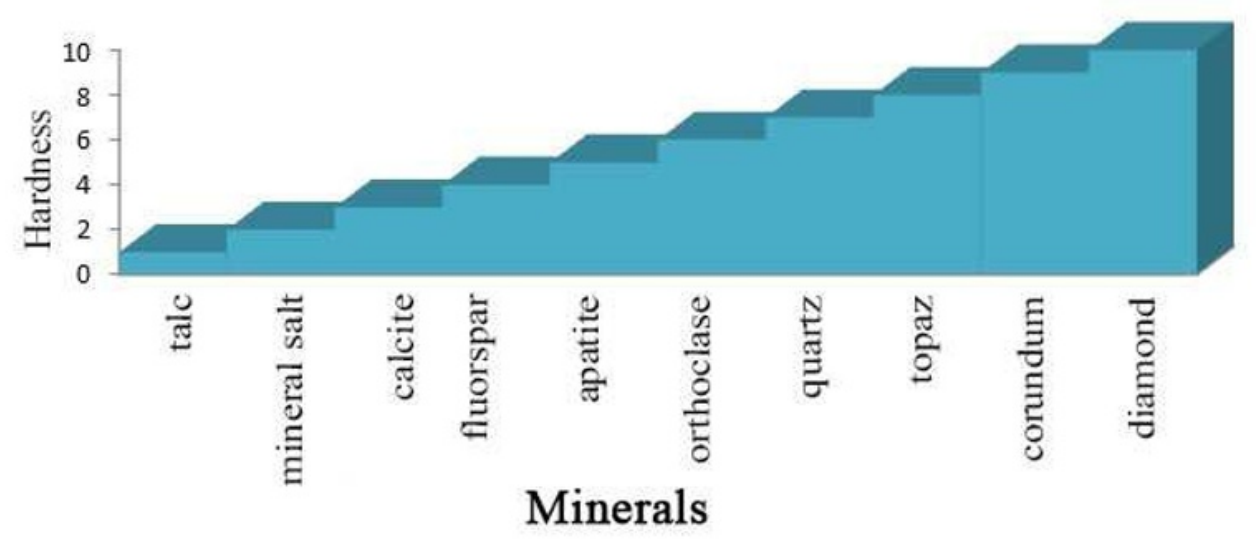

Fig. 1 Relative hardness of minerals according to the Mohs scale

Figure 1 shows that talc is the softest mineral and its value on the Mohs scale equals 1 . This means that talc can be easily carved with a nail. The second position is occupied by rock salt. Unlike talc, it is not so easily affected by a mechanical action. Calcite is ranked 3rd on the Mohs scale. This means that its surface can be easily carved with a knife. Fluoric spar and apatite have approximately the same hardness and their value on the Mohs scale equals 4.5. Their surface can be easily carved with glass, as well as with a knife. The hardness of orthoclase on the Mohs scale is 6 and only glass can leave faint traces on its surface. The hardness of quartz, topaz, corundum and diamond on the Mohs scale is 6,7, and 8 , respectively. They scratch glass easily.
Abrasiveness is the ability of rocks to affect the wear of the downhole equipment during well drilling. Rocks composed of grains of hard minerals cemented by a less durable material exhibit abrasive properties. Quartz sandstones have the highest abrasive properties. To a lesser extent, abrasiveness depends on the grain roundness. As the rotation speed of the drill bit increases, the wear of the rock cutting equipment usually increases faster than the drilling rate.

The rock density is defined as its mass-to-volume ratio, or as the degree to which a certain volume is filled with minerals. Sedimentary rocks exhibit the lowest density, and igneous rocks have the highest density. The density of rocks depends on the mineralogical 
composition of the grains and the binding cement. The ratio of the sample mass to its total volume characterizes the average rock density, which depends on the material composition and porosity. These properties play a crucial role in drilling processes, as they determine the conditions for transporting particles of destroyed rock to the surface. Porosity, which is characterized by the presence of voids in the rock, is of high relevance, since the mechanical strength, abrasiveness, moisture capacity and other properties of rocks directly depend on it. Porosity is determined by the ratio of pore volume to rock volume. The porosity of igneous rocks is the smallest and is measured in fractions or percent of the volume.

Physical and mechanical properties of rocks play an important role in drilling. To increase the drilling rate and to modernize drills, it is necessary to consider all physical and mechanical properties of rocks. The modernized DTH drill proposed in the paper is the best solution to the problem, since its use allows controlling the percussion action due to the air flow. The control of the percussion action increases the drilling rate. When rocks with high abrasiveness and elasticity are detected, hitting a roller bit allows bypass of these complex rocks.

\subsection{Analysis of possible modernization of SBSh- 250}

In order to analyze the ways to improve drilling operations in open pits, it is necessary to set the task, define the process and carry out the correct division of the process into functions with a sufficient number of technical implementations. In our opinion, this can be formulated as follows: Intensification of drilling of blast holes in hard rocks or Investigation of ways to improve the efficiency of intensification of drilling of blast holes in open pit mining during development of hard rocks. Consider the conditions that hinder the process of drilling rocks. Figure 2 shows the percentage of conditions that decrease the productivity of rock drilling.

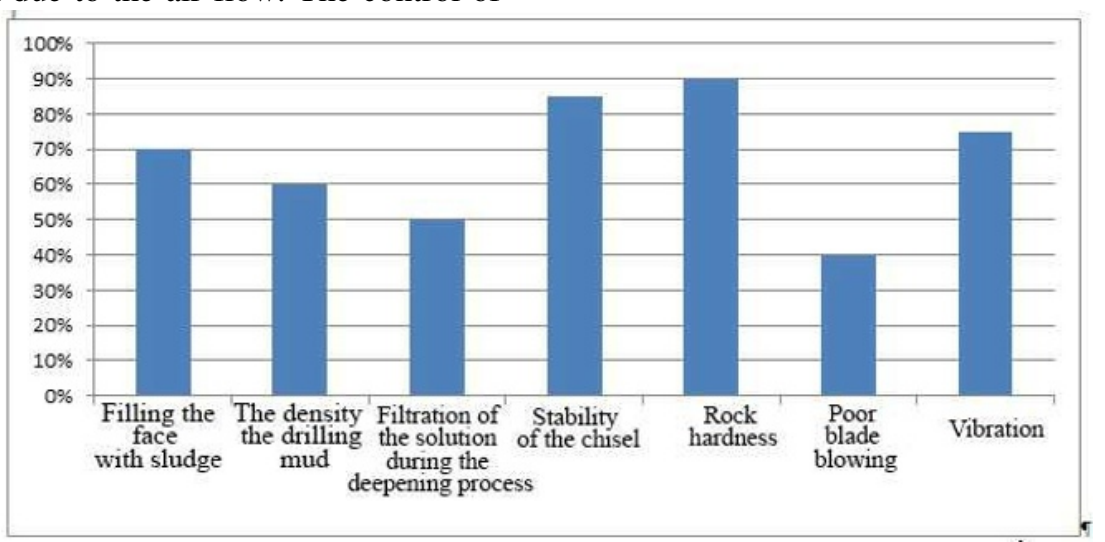

Fig. 2 Percentage dependence of conditions that decrease the drilling rate in SBSh

The analysis shows that all the listed conditions that reduce the productivity of rock drilling necessitate the use of a DTH pneumatic hammer. Control of the DTH hammer operation can increase the drilling rate and decrease the percentage of failure of drill rigs.

When drilling complex rocks, the driver can observe the indicators on the monitor, track the drilling rate and, if necessary, turn on the DTH hammer.

The analysis of the percentage dependence shows that the rock hardness and other factors affecting the decrease in the drilling rate can be eliminated due to the DTH pneumatic hammer. In some cases, there is not need to use the entire hammer since less hard rock may be encountered in drilling. To develop this section, a hammer can be employed, and then it is possible to carry out drilling without it. In this case, we propose to regulate the drilling rate using a valve. This helps increase the durability of the roller cutter bit, since the impact on the roller cutter is less significant.

A preliminary morphological analysis of the drilling intensification process carried out by SPGU experts and specialists from JSC Apatit showed:

1. To improve the drill rigs for roller drilling, it is advisable to use the DTH hammer (hydraulic hammer) with damping percussion action and forming L-shaped shock impulse. This should increase the drilling rate due to a more complete adherence of the cutter to the bottom, increase the concentration of shock load on the blades, and lead to better cleaning of the cutter blades (pins).

Specific schemes of the drill string with a percussion mechanism at a given impulse shape can be implemented through creation of hollow percussion pistons with a special filling, which are currently being experimentally tested and patented, and therefore are not reported in this paper.

2. Versions with a high priority in terms of impact on the environment (humans) need reduction of the harmful effect of the drill string vibration. This can be done as follows:

- installation of damping devices (hydraulic shock absorbers) between the drill string and the rotation head assembly;

- installation of damping devices (hydraulic shock absorbers) between the rope and the feed hydraulic cylinder;

- installation of a removable cabin (it does not reduce the harmful effects of vibration on the machine as a whole, and, especially, on the drive of the rotator and the support); 
- installation of pneumatic accumulators in the pressure supply line of the hydraulic feed jack;

- installation of the tracking system to reduce the natural vibration frequency of the string (this option is difficult to implement practically) by controlling the frequency of percussion action of the down-the-hole hammer.

When using fully electrified drill rigs, the most effective means is to install shock absorbers between the string and the rotation head. It is advisable to supply hydraulic-powered machines with pneumatic-hydraulic accumulators in the pressure supply line of the hydraulic feed jack.

\subsection{Modernized SBSh-250}

The analysis of all possible options for drilling rocks revealed some problems. For instance, vibration and noise lead to faster wear of the bearings in a roller cone bit. To solve such problems, it was proposed to control the hammer operation using an adjustable valve that regulates the air flow.

Below is a scheme of a new modernized drill rig, which consists of 1 - roller cutter; 2 - pneumatic hammer; 3 - cabin; 4 - drill string; 5 - retransmitter; 6 receiving and transmitting device; 7 - antenna; 8 control unit with a monitor; 9 - supply, 10 - running gear.

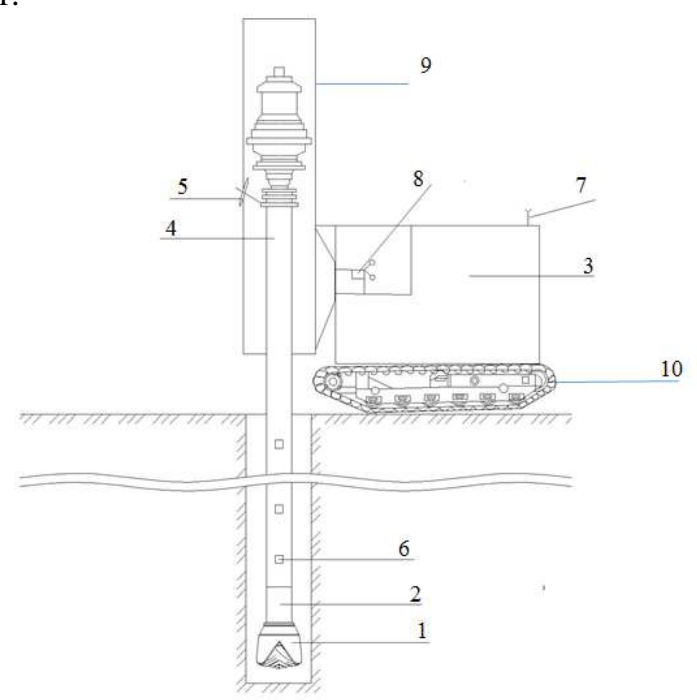

Fig. 3 Modernized SBSh-250

The device for regulating the air flow in the drill string of the drill rig includes the device (Fig. 3), the drill rig for rock destruction by shock impulses includes a rock cutting tool - roller cutter 1 . Roller bits are widely used when drilling blast holes in quarries and in underground mining. When rolling the cutter along the bottomhole, its teeth penetrate into the rock, which is destroyed by crushing. In soft and medium-hard rocks, the so-called teeth slipping mode is carried out, when the rock shavings are chipped (sheared). The roller bit is connected to hammer 2 with the ability to remove.

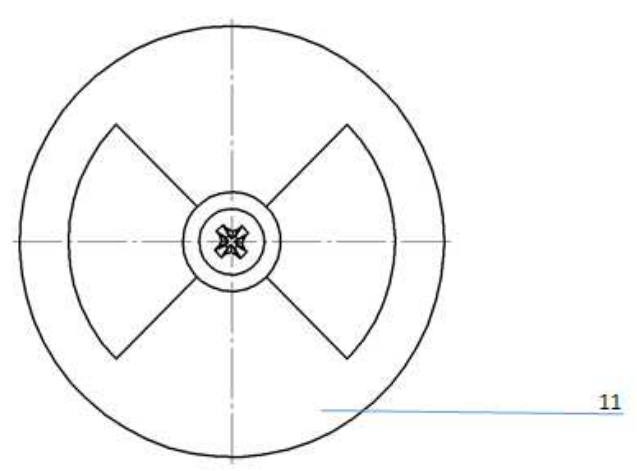

Fig. 4 Valve in open position

When drilling a homogeneous soft massif, the device functions as follows: valve 19 is closed, hammer 2 does not work, and the air bypassing hammer 2 through air channels 12 goes only for blowing the well.

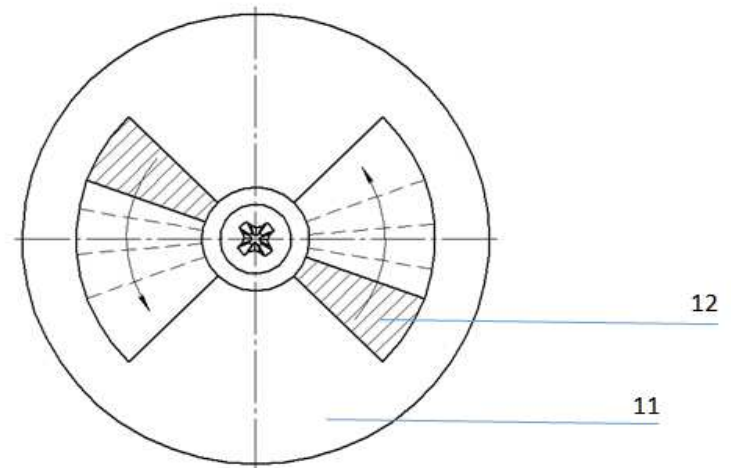

Fig. 5 Valve in half-open position

When drilling vertical wells in hard rock massifs of complex structures, for instance, granite, it is required to turn on hammer 2 to maintain a high drilling rate. The driver transmits the Opening signal from the control unit with monitor 8 through antenna 7 to retransmitter 5 and then to receiving and transmitting device 6 , and then to valve control unit 12 . At the same time, the switch is activated and the battery is connected, which turns on the worm gear drive of adjustable valve 12 through the cable. Once the worm gear is activated, the drive shaft of the valve is set in motion to open adjustable valve 12 . The compressed air through the rig compressor enters hammer 2 through drill string 4, while the hammer piston begins to strike the cutter shank to stabilize the drilling process: the drilling rate increases, the vibration level normalizes, the 'wedging' of the cutter is eliminated, the well blowing is intensified, the 'cushion' of drilling fines at the bottom is eliminated, the bottom surface is leveled, and so on. The power and frequency of percussion action of pneumatic hammer 2 depends on the degree of opening of adjustable valve 12 . To reduce the drilling rate, the Close or Throttle down signal is transmitted from the control unit with monitor 8 through antenna 7 to retransmitter 5 , then to receiving and 
transmitting device 6, and then to the valve control unit. At the same time, the switch is triggered and the battery is connected to activate worm gear drive 9 of adjustable valve 12 through the cable. Once the worm gear is activated, the valve drive shaft is set in motion, adjustable valve 12 is partially or completely closed. The flow of compressed air that enters through the compressor, drill string 4 and air channels into hammer 2 becomes weaker or, when completely closed, air is cut off from hammer 2 .

The technical result of the proposed design is the creation of a device for increasing the drilling rate and bit durability, and enhancing the safety of work.

\subsection{Theoretical studies of the permissible percussion action on the roller cutter}

To calculate the permissible percussion action in order not to destruct the bit, take the metal with the minimum tensile strength and its sectional area in the bit with regard to the safety factor.

From the condition of non-destruction of the bit in the dangerous section (in the shoe), it is possible to form an inequality to determine the value $P_{O C}^{y A}$ :

$$
P_{O C}^{\text {уд }} \mathrm{J} \frac{\left[\sigma_{\text {Сж }}\right] 4 S_{3}}{k_{\text {зап }}}-\left(P_{O C}^{*}+P_{O C}^{\pi}\right)
$$

By changing the safety factor and using the previously calculated values, determine the minimum and maximum values of the axial force when using percussion action of the DTH hammer.

a) when using a roller cone bit $\propto 75 \mathrm{~mm}$ made of 12XH2 steel for bench testing:

$$
\begin{aligned}
& P_{O C_{\min }}^{\text {уд }} \mathrm{J} \frac{730400}{1,3}-\left(4,940^{3}+3040^{3}\right)
\end{aligned}
$$

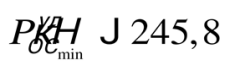

$$
\begin{aligned}
& P_{O C_{\max }}^{y A} \mathrm{~J} \frac{730400}{1,05}-\left(4,940^{3}+3040^{3}\right) \\
& \text { PКस J 312, } 7
\end{aligned}
$$

b) when using a roller cone bit a $244 \mathrm{~mm}$ made of 19HGNMA steel used for SBSh-250:

$$
\begin{aligned}
& P_{O C_{\text {min }}}^{\text {уд }} \mathrm{J} \frac{7304000}{1,3}-(59,4+215) \\
& \text { PKKH J } 287
\end{aligned}
$$

In the case of a decrease in the safety factor:

$$
P \text { KKस } H_{\max } \mathrm{J} \frac{7304000}{1,05}-(37,3+215)=442,9
$$

Hence, it can be seen that there is a significant margin of axial force, which can be realized in percussion action using the DTH hammer without destroying the bit.

Then:

$$
P_{\text {oc }}=b_{c}^{*}+b_{c}^{n}+P^{k} H \neq 4,9+30+(245,8 \text { ë } 312,7)=280,7 \ddot{e} 347,6
$$

\section{Conclusions and recommendations}

The valve control helps stabilize the drilling rate and extend the roller cutter durability by regulating the air flow through the hammer. This will improve the operating conditions of the roller cutter and intensify the destruction of the bottomhole.

\section{References}

1. D.A. Yungmeister, V.N. Brichkin, A.I. Isaev 2019 Ore dressing 2 3-7

2. D.A. Yungmeister, A.I. Isaev, A.I. Yacheykin, P.D. Soboleva MIAB. Mining Informational and Analytical Bulletin, 3, 28-36, (2021)

3. A.A. Khrutskiy, V.S. Oshchepkov Mining information and analytical bulletin (scientific and technical journal) 7, 131-138, (2018)

4. R.I. Sukhov, V.S. Bolkisev, A.S. Regotunov Mining equipment and electromechanics 5, 4648, (2014)

5. Mohammad Ataei, Reza KaKaie, Mehdi Ghavidel, Omid Saeidi International Journal of Rock Mechanics and Mining Sciences 73, 130138, (2015).

6. N. S. Heshamudin, A. Katende, H. A. Rashid, I. Ismail, F. Sagala, A. Samsuri Journal of Petroleum Science and Engineering 179, 11731185 (2019) DOI: 10.1016/j.petrol.2019.04.086.

7. Z. Guo, Z. Liang KSCE Journal of Civil Engineering 22, 5133-5142 (2018) DOI: 10.1007/s12205-018-0481-0.

8. A. Vardhan, A. Kumar, K. Dasgupta Journal of Mines, Metals and Fuels 65(2), 49-54, (2017).

9. I.A. Zhukov, B.N. Smolyanitskiy Mashinostroyenie, 1, 27-31, (2018)

10. I.A. Zhukov, E.G. Timofeev Application of information technologies in solving the problem of rationalizing shock impulses generated in shock machines. (Sevastopol: Sevastopol State University, 2018)

11. I. A. Zhukov, B. N. Smolyanitsky, V. V. Timonin Journal of Mining Science 2(54), 212-217, (2018).

12. V.I. Bolobov, T.B. Le, V.A. Plashchinsky Processing of ores 6 3-8 (2019)

13. V.I. Bolobov, S.A. Chupin, V.S. Bochkov, I.I. Mishin Mining journal 5 67-71 (2019)

14. I. A. Zhukov, B. N. Smolyanitsky, V. V. Timonin Journal of Mining Science 2(54) 212-217 (2018)

15. V. I. Bolobov, S. A. Chupin, L. T. Binh IOP Conference Series: Earth and Environmental Science 459(6) 62080-62085, (2020)

16. M. V. Dvoynikov, A. A. Kunshin, P. A. Blinov, $\mathrm{V}$. A. Morozov International Journal of Engineering (IJE), IJE TRANSACTIONS A: Basics 7(33) 1423-1430, (2020)

17. M. V. Dvoynikov, M. V. Nutskova, P. A. Blinov International Journal of Engineering, Transactions A: Basics 33(4) 702-711 (2020). 
18. Poderni R.Yu. Mechanical equipment quarries: a Textbook for universities, 8th edition, (Moscow, Izd-vo «Mayning Media Grupp», 2013) 